\title{
AS ESCOLAS FEMININAS DE INSTRUÇÃO PRIMÁRIA EM SÃO JOSÉ DOS PINHAIS NOS ANOS FINAIS DO SÉCULO XIX. ${ }^{1}$
}

Eliane Mimesse. emimesse@bol.com.br

Luciane Palaro. lucianepalaro@bol.com.br

Universidade Tuiuti do Paraná - UTP

\section{RESUMO:}

Visa-se a análise do processo de criação e implantação das escolas públicas femininas de instrução primária na localidade de São José dos Pinhais, Estado do Paraná. A primeira cadeira feminina foi criada em 1854. A pesquisa tem caráter bibliográfico documental, as fontes primárias utilizadas estão alocadas no acervo do Arquivo Público do Estado do Paraná. Na documentação estudada foram verificados relatórios manuscritos dos professores ao Inspetor Escolar e dos Inspetores ao Presidente da Província, além dos Relatórios dos Presidentes da Província. Uma pequena parcela desses documentos tornouse inacessível devido às agruras do tempo. Conclui-se que mesmo com os obstáculos constantes no desenvolvimento da educação primária, a cidade de São José dos Pinhais manteve em funcionamento suas escolas femininas.

Palavras-chave: educação feminina; instrução primária; história da educação.

\section{GIRLS' PUBLIC SCHOOLS IN PRIMARY EDUCATION IN SÃO JOSÉ DOS PINHAIS IN THE FINAL YEARS OF THE CENTURY XIX.}

\begin{abstract}
:
This research aims at analyzing the process of constitution and implementation of girls' public schools in primary education in São José dos Pinhais, in Paraná State. The first woman chair was established in 1854. The documental sources are from Paraná State Archives. This research has documental bibliographical character. In the studied documentation hand written reports were verified of the teachers to the School Inspector and of the Inspectors to the President of the County, besides the Reports of the Presidents of the County. Only one small fragment of these documents was unfeasible due to its seriously deteriorated condition. In conclusion, even with the constant restrictions in the development of primary education, the city of São José dos Pinhais was able to provide for its girls' schools.
\end{abstract}

Keywords: feminine education; primary instruction; history of education.

\section{Introdução}

Nesse estudo pretendemos analisar como ocorreu o processo de criação e implantação das escolas públicas femininas de instrução primária na localidade de São José dos Pinhais. As razões para tanto se centraram nas inquietações em torno dos motivos pelos quais o governo da Província do Paraná assinou decretos de criação de escolas 
femininas em uma localidade próxima da Capital. Constatou-se que a capital da Província apresentava defasagem de escolas desta modalidade. A criação da primeira cadeira feminina de instrução primária ocorreu no ano de 1854, mais de duas décadas após a criação da cadeira do sexo masculino (PARANÁ, 1854), demonstra desta forma que sua criação não era um privilégio, nem uma concessão às meninas que estavam em idade escolar.

Uma das hipóteses levantadas a partir desta análise foi o incentivo à educação, presente nos discursos do Presidente da nova Província do Paraná, Zacarias de Góes e Vasconcelos (PARANÁ, 1854) ${ }^{2}$. Esse presidente foi empossado em 1853, logo após a efetivação da emancipação política da então $5^{a}$ Comarca da Província de São Paulo. Durante o seu governo e nos que o sucederam pôde-se verificar a manutenção do discurso com ênfase na educação. Apesar de existirem comprovadamente, segundo o levantamento efetuado nos documentos, três agravantes imediatos: a dificuldade em preencher as vagas para professores, o baixo número de alunos freqüentes nas escolas em funcionamento e a defasagem de utensílios escolares nas salas de aulas (PARANÁ, 1854).

A manutenção na ênfase do discurso sobre a educação por parte do governo provincial pôde ser verificada na documentação pesquisada, durante a maioria dos anos finais do século XIX, no período após a emancipação da Província de São Paulo. Contudo, verificou-se uma defasagem na documentação arquivada e disponibilizada para a consulta no acervo do Arquivo Público do Estado do Paraná. Não foram encontrados documentos referentes aos quinze últimos anos do século XIX, que tratassem do objeto deste estudo. Foram levantadas algumas hipóteses para tal fato: pode-se inferir sobre a suspensão no envio de relatórios pelos professores aos inspetores, no arquivamento da documentação em acervos diferenciados ou mesmo na própria localidade, ou ainda, no extravio de documentos e nas intempéries do clima, que dependendo de como ocorreu o armazenamento da documentação implicou em uma conservação equivocada.

\section{O uso das fontes documentais.}

É primordial enaltecermos logo de início o uso das fontes primárias para a composição desta pesquisa. $O$ trabalho de pesquisa exige uma atenção ampla com $o$ material a ser trabalhado, no sentido de perceberem-se todas as nuances que o envolvem. Os acontecimentos históricos devem ser questionados, para que possam ser verificados segundo o entendimento do pesquisador que o inquire, quais são os caminhos e pontos que guarda. Sempre se deve analisar sob todos os ângulos possíveis o objeto colocado como centro de uma investigação, para evitarem-se os enganos.

A prática de pesquisar comporta uma série de variantes e de determinantes em seu trajeto. Quando não existe o acesso a todos os documentos que possibilitem o desvendamento dos acontecimentos de modo detalhado, deve o pesquisador, direcionar-se a outros tipos de documentos e fontes que contribuam para a reconstituição de seus dados. A busca por indícios no entorno do contexto é parte implícita a uma pesquisa em história da educação. A verdade detectada em um determinado acontecimento, nunca será a realidade pura, como ocorreu, porque estamos sempre fazendo uma reinterpretação do que se passou. É necessária, deste modo, a elaboração de hipóteses, por contribuírem com os questionamentos a serem feitos aos documentos. O caminho seguido nesta pesquisa foi determinado em função das hipóteses levantadas. Essas hipóteses foram analisadas, comprovadas ou não e, suscitaram outras hipóteses. Como nos alertou Certeau (2002, p. 34) não podemos nos esquecer "que uma leitura do passado, por mais controlada que seja 
pela análise dos documentos, é sempre dirigida por uma leitura do presente." Sendo assim, as hipóteses foram implícitas e inevitáveis a esta e a qualquer modalidade de pesquisa.

$\mathrm{Na}$ análise da documentação foi necessário ir além das aparências dos acontecimentos e dos conteúdos que estes demonstravam. Fez-se necessário investigar outras áreas e disciplinas que envolviam o objeto estudado, pesquisando-se a sociedade como um todo. As fontes primárias documentais aqui utilizadas podem ser encontradas no acervo do Arquivo Público do Estado do Paraná, este pode ser considerado o responsável pela guarda e manutenção dos mais diversos documentos relacionados a história do Estado, porque:

[...] os arquivos compõem o mundo do jogo técnico, um mundo onde se reencontra a complexidade, porém, triada e miniaturizada e, portanto, formalizável. Espaço preciso em todos os sentidos do termo; [...] o equivalente profissionalizado e escriturário daquilo que representam os jogos na experiência comum de todos os povos, quer dizer, das práticas através das quais cada sociedade explicita miniaturiza, formaliza suas estratégias mais fundamentais, e representa-se assim, ela mesma, sem os riscos nem as responsabilidades de uma história a fazer. (CERTEAU, 2002, p. 20)

Os documentos utilizados desvendaram parte da história das escolas de instrução primária da localidade de São José dos Pinhais, nas páginas que se seguem pretendemos adentrar no cotidiano destas escolas. A escrita original da documentação foi mantida nas citações que complementam esse artigo.

\section{As escolas de instrução primária.}

A educação foi colocada como prioridade no governo do novo presidente da Província do Paraná Zacarias de Góes e Vasconcelos. Normalmente o presidente de uma Província era uma pessoa nomeada pelo Imperador, eram indivíduos conhecidos e que gozavam de certo prestígio na Corte. Góes e Vasconcelos criou, logo após sua posse, um programa de desenvolvimento para a educação no Paraná. Verificou-se na análise a intenção de uma uniformização no ensino (PARANÁ, 1854). Segundo Vecchia (1998) essa ação possibilitou a determinação de que todos os professores da Província devessem utilizar os mesmos compêndios e os mesmos métodos de ensino.

A legislação que vigorou inicialmente na nova Província do Paraná, para a educação, continuou sendo a de São Paulo, criada em 16 de março de 1846. Segundo esta lei, deveriam existir escolas específicas para cada um dos sexos, porém seria necessário o mínimo de 12 alunos para a criação de uma cadeira, como referenciado por Vecchia (1998). Caso não houvesse essa determinada quantidade de meninas na abertura de uma escola feminina, elas deveriam estudar com os meninos tornando-se uma escola denominada como promíscua, contudo, o presidente Góes e Vasconcelos considerava essa ação intolerável e só em último caso deveria ocorrer. (PARANÁ, 1854)

Na localidade de São José dos Pinhais, atualmente situada na área metropolitana da cidade de Curitiba, a primeira cadeira de instrução primária foi criada no ano de 1831, e de acordo com Colnaghi (1992) era destinada somente ao sexo masculino. O presidente da Província tinha a pretensão de criar em cada cidade, no mínimo, uma cadeira para cada sexo. Porque segundo esse presidente a importância da cadeira do sexo feminino era a mesma que a do sexo masculino. 
[...] se fosse tão pobre esse município que não tivesse 12 alumnas para comparecer às aulas, deveriam dar a uma professora particular uma gratificação para que ela ensinasse a quantidade de meninas que houvesse. O Presidente chega a lamentar, pois acha uma pena que não haja em São José uma escola de primeiras letras para o belo sexo, pois é raro uma mãe que sabe ler e escrever e não ensina seus filhos nas horas vagas, por este motivo instruir as meninas seria como criar uma escola em cada família. (PARANÁ, 1854, p.19)

Dessa forma, foi criada a primeira cadeira de instrução pública do sexo feminino em São José dos Pinhais, no ano de 1854. Colnaghi (1992) acrescentou ainda a informação de que essa cadeira teve como professora Anna Joaquina Alves de Jesus, que foi contratada pela Província para ocupar a cadeira vaga. Em março do mesmo ano a professora Anna Joaquina se inscreveu e solicitou que fosse marcado o dia e hora para fazer o concurso para tornar-se professora vitalícia. Tempos depois ela fez o exame e foi aprovada, sendo promovida ao novo cargo, tornando-se assim professora titular da escola (PARANÁ, 1869).

As matérias lecionadas nas escolas primárias elementares femininas eram as mesmas que as dos meninos, porém o conteúdo de geometria não era ensinado, a aritmética era limitada a teoria e somente as quatro operações eram feitas na prática, as meninas ainda contavam com aulas de prendas domésticas. Segundo Vecchia (1998) as outras matérias que ambos os sexos aprendiam em comum eram: leitura, escrita, gramática da língua nacional e princípios da moral cristã e da doutrina da religião oficial. A inspeção do ensino religioso, moral e intelectual estava a cargo dos vigários e em São José dos Pinhais, de acordo com o Relatório do Presidente da Província datado de 01 de março de 1856, o inspetor do ensino religioso, moral e intelectual era o Padre João Batista Ferreira Bello (PARANÁ, 1856).

Entretanto, os argumentos morais da sociedade da época não julgavam relevantes aprendizagens dos mesmos conteúdos para os dois sexos. Afinal por que uma mulher deveria aprender geometria ou aritmética se ela ficaria em casa cuidando da família e de seus afazeres domésticos?. O ensino feminino era voltado para uma forma de educação onde a mulher era preparada para ser mãe e dona de casa. Era desta maneira, conhecedora da leitura, para poder ler os ensinamentos sagrados e repassá-los aos seus filhos, como explicitou Soares de Almeida (2007). Deste modo, ensiná-los-ia conseqüentemente os rudimentos das Primeiras Letras: ler, escrever e contar. Essas mulheres deveriam adquirir também habilidades com os trabalhos manuais, para assim poderem preencher o seu tempo livre.

Algumas considerações sobre o calendário e os horários de funcionamento das escolas devem ser indicados neste momento, conforme Mimesse (2010). A Instrução Pública no Império estabelecia os horários de funcionamento e os dias feriados para as escolas existentes; depois da proclamação da República em 1889, a divisão do tempo nas escolas modificou-se. Desde o início do século XIX, quando as escolas de São José dos Pinhais foram criadas, até finais do referido século, o horário de funcionamento das escolas era das oito horas da manhã até uma hora da tarde. O calendário escolar e os dias considerados feriados nas escolas públicas, durante o Império eram:

$1^{\circ}$ A quinta feira de cada semana, quando nella não houver dia santo ou feriado.

$2^{\circ}$ Os domingos e dias santificados.

$3^{\circ}$ Os dias de grande gala, ou de festa nacional.

$4^{\circ} \mathrm{O}$ dia 26 de fevereiro. 
$5^{\circ}$ Os de entrudo e quarta feira de cinza.

$6^{\circ}$ Os que decorrem do domingo de Ramos ao da Paschoa.

$7^{\circ} \mathrm{O}$ de finados.

$8^{\circ}$ Os que decorrem de 8 de dezembro a 6 de janeiro. (MIMESSE, 2010, p.42)

No ano de 1856 foi publicado um novo plano de divisão do ensino. A partir do mês de dezembro deste referido ano esse plano passou a ser colocado em prática nas escolas. Essa deliberação do vice-presidente da Província instituía que as escolas seriam divididas em três classes. Essa divisão pode ter ocorrido com a finalidade de ordenar os alunos durante o período das aulas. (PARANÁ, 1856). Era uma forma de o professor conseguir ter um controle mais eficiente sobre seus alunos. Desta forma, as crianças começavam desde cedo a inculcar as várias formas de disciplina impostas pelo governo.

Em São José dos Pinhais, as aulas eram ministradas normalmente na casa do próprio professor. Existem registros que contêm a indicação de que casas eram alugadas no centro da localidade para que servissem como escolas (PARANÁ, 1869). Na maior parte dos documentos deparamo-nos com as reclamações constantes sobre a falta de utensílios em sala de aula, e mesmo os poucos que haviam estavam deteriorados, por este motivo o pedido de mobília era reiterado por parte dos professores (PARANÁ, 1855). Em todos os relatórios enviados pelos vários professores da localidade pôde-se verificar que a falta de utensílios era recorrente. Em pesquisa realizada em uma colônia de italianos na mesma época, Mimesse (2010), apontou que as dificuldades com a aquisição dos materiais eram cíclicas.

Desta forma, não eram raros os pedidos feitos à Tesouraria Provincial solicitando o pagamento do aluguel das casas onde funcionavam as escolas. Como exemplo pode-se citar o fato ocorrido no dia 17 de abril de 1855, com o professor interino Manuel Gonçalves de Oliveira, relatado em carta enviada por este professor ao Inspetor da Instrução Pública de São José dos Pinhais (PARANÁ, 1855). Esse professor lecionava para os alunos do sexo masculino e, solicitou que fosse pago o valor anual de 24 mil réis do aluguel da casa que estava sendo utilizada como escola. Foi por ele anexado o contrato de aluguel que foi pago no mês de março às suas custas, e solicitou ainda que lhe fossem enviados com urgência 2 mil réis que lhe eram de direito, por ter sido ele o responsável pelo pagamento do aluguel no mês de março. O padre João Batista Ferreira Bello, reconhecido por sua idoneidade na comunidade e inspetor nomeado do ensino religioso, moral e intelectual atestou a veracidade das informações daquele professor (PARANÁ, 1855).

No dia 15 de novembro de 1864, o Inspetor Geral da Instrução Pública, Joaquim do Carmo, concedeu licença de três meses para o professor e para a professora das escolas de Primeiras Letras, masculina e feminina, localizadas em São José dos Pinhais. Ambas as licenças eram referentes aos cuidados com a saúde (PARANÁ, 1864). Mas, não foram nomeados outros professores como substitutos para assumirem as referidas cadeiras, tendo os alunos permanecido sem os professores durante esse período e conseqüentemente sem freqüentarem as aulas até o mês de janeiro do ano de 1865, quando os dois professores reassumiram normalmente suas escolas (PARANÁ, 1870). A hipótese para essa ação conjunta é a de que os professores fossem casados, e necessitavam desse período para procurarem novas acomodações no local para o qual foram transferidos. Mas, nenhuma documentação referente especificamente a este fato foi encontrada.

No ano de 1868, a professora Amélia Isolina de Carvalho Bordes assumiu a cadeira de Primeiras Letras para o sexo feminino de São José dos Pinhais. Essa professora conseguiu fazer com que se matriculassem "a muito rogo" dezessete meninas. No mesmo 
documento a professora ainda esclareceu que dessas dezessete meninas, quinze delas eram analfabetas e as outras duas que restaram sabiam ler e escrever. Mas, essas duas alfabetizadas freqüentaram as aulas da escola feminina apenas por alguns meses, porque apresentavam um grau muito alto de adiantamento comparado aos das outras alunas (PARANÁ, 1869).

Analisando as palavras da professora Amélia Carvalho, podemos perceber que ela teve que insistir muito para que as meninas da localidade de São José dos Pinhais fossem matriculadas na escola. Quando a professora anotou em seu relatório que somente a "muito rogo" ela conseguiu garantir a matrícula das alunas, torna-se perceptível a falta de motivação dos pais em matricular suas filhas na escola de Primeiras Letras. Uma hipótese para essa ação é a de que desde muito pequenas, as meninas ajudavam a cuidar dos irmãos mais novos e também dos afazeres domésticos, e consequentemente, não seria conveniente aos pais disporem de tão preciosa fonte de trabalho. Foram constatadas que as meninas contribuíam com os trabalhos desenvolvidos por suas mães, tias ou outras mulheres próximas da família. O trabalho das meninas envolvia a manutenção da casa, o cuidado com os pequenos animais, o preparo das refeições e a organização das vestimentas a serem lavadas e colocadas para secar.

Desse fato decorre que, enquanto as meninas estivessem na escola elas não poderiam ajudar a família com suas tarefas, o que não era bem visto pelos pais, porque a maioria delas vinha de famílias humildes e sem condições financeiras para manterem as filhas por muitos anos na escola. E, como reitera Soares de Almeida (2007, p. 93) "a mentalidade vigente desde a colônia dava pouco valor à instrução feminina, concentrando sua atenção nas normas sociais que impediam as mulheres de ocuparem espaços sociais".

No ano de 1870, uma reclamação constante foi encontrada durante as leituras e análises dos relatórios assinados pelo Presidente da Província Affonso de Carvalho. Esse presidente apontava que "no Paraná tem se escrito muito sobre a instrução pública, porém pouco se tem praticado". (PARANÁ, 1870). Ele indicava ainda a permanência da falta de confiança em certos professores e a precária formação acadêmica, como as principais razões das inaptidões dos alunos durante os exames finais.

Para o presidente Affonso de Carvalho era imprescindível a criação de uma Escola Normal na capital da Província, com o objetivo de habilitarem-se pessoas destinadas ao magistério da instrução pública (PARANÁ, 1870). Esse parecia ser o remédio necessário e eficaz para este mal, entretanto, o plano de construção de uma Escola Normal ficou apenas nos discursos do presidente, a Província nessa época não dispunha de recursos para tamanho empreendimento, como o da construção de um edifício próprio para essa escola.

No mês de dezembro eram feitos os exames finais. No ano de 1870 a professora Amélia Carvalho remeteu um termo solicitando que fossem marcados os dias e as horas para os exames finais. Entretanto, apenas uma aluna de sua turma estava apta para ser examinada. Essa aluna era Eugenia Ferreira de Oliveira Prestes. Quando da solicitação para o agendamento dos exames finais a mesma professora solicitou a nomeação de um examinador ao Inspetor Geral da Instrução Pública (PARANÁ, 1870).

Desde o ano de 1868, quando a professora Amélia Carvalho tomou posse da cadeira do sexo feminino de Primeiras Letras da localidade, ainda não havia conseguido enviar nenhuma aluna para exame. A aluna Eugênia Ferreira de Oliveira Prestes foi a primeira mulher em São José dos Pinhais a prestar o exame final do curso de Primeiras Letras. Inúmeros foram os motivos que fizeram com que as sãojoseenses não prestassem esse exame no final do ano, sendo um dos principais o fato de elas terem de ajudar seus pais nos afazeres domésticos, como abordado por Soares de Almeida (2007). 
Em 1870, o então Presidente da Província Antonio Luiz Affonso de Carvalho, enfatizou em relatório datado de 15 de fevereiro que "sem a religião a educação é nenhuma, sem a educação a instrução é talvez um perigo" (PARANÁ, 1870, p. 3). Nas palavras deste Presidente, verificamos que a religião estava profundamente internalizada na educação e na transmissão dos valores para os alunos da Província nesta época. Esse discurso presidencial era uma apologia à religião oficial do Estado - a católica, onde ficou claro que naquele momento a educação, o Estado e a religião estavam caminhando de mãos dadas e em determinados momentos se confundiam entre si. Prova disto é que a partir de então, a inspeção do ensino religioso, moral e intelectual ficou a cargo dos párocos, sendo que eles também poderiam interferir a qualquer momento no que fosse referente a esses assuntos.

Em São José dos Pinhais a designação dos párocos foi além das aulas de ensino religioso. Com a nomeação do padre João Batista Ferreira Bello como Inspetor responsável da Comarca no ano de 1856, como citado anteriormente, a religião perpassou quase todos os ensinamentos das Primeiras Letras, desde cânticos até orações, com o intuito de contribuir com as aulas de escrita e leitura. Desde esta época já existia a preocupação em fazer com que a educação e a religião caminhassem juntas, uma a serviço da outra. No ano de 1871, de acordo com Vecchia (1998), quando foi implantada a Reforma do Ensino, percebeu-se que a religiosidade era fortemente marcada, a rigidez era tamanha ao ponto de que se algum professor quisesse ingressar no magistério público era obrigado a professar a religião oficial do Estado.

Mais uma vez a religião se fortaleceu dentro das escolas e dentro do poder governamental, porém agora de uma forma mais ampla e sólida. Mas, o que não se cogitava neste momento era a chegada dos imigrantes. Esses imigrantes começaram a entrar no país em grande escala, devido à necessidade de mão-de-obra para a agricultura. Na Província do Paraná o número de italianos, poloneses, alemães e ucranianos, era demasiado grande para ser ignorado pelas autoridades. Muitos desses novos habitantes da Província não professavam a religião católica, e como poderiam conviver com escolas públicas que mantinham o catolicismo como religião oficial?. Mas, essa é outra discussão, cada colônia encontrou formas de educar suas crianças dentro de suas tradições morais e culturais. Quanto às escolas, especificamente do centro da localidade de São José dos Pinhais nenhum tipo de incidente deste porte foi verificado na documentação.

Contudo, no ano de 1874 o Presidente da Província em exercício Frederico Cardoso de Araújo Abranches, sancionou um novo regulamento. De tal modo que diminuísse a ênfase dada ao ensino religioso, mas, destacou a importância e manteve a necessidade dos padres permanecerem como conselheiros na Instrução Pública (PARANÁ, 1878). Neste momento, os laços que atavam o Estado e a Igreja em torno da educação, na Província do Paraná, começaram a ser desvencilhados e aos poucos a educação laica e nacionalizante foi tomando um espaço cada vez maior, fazendo com que o ensino de cunho religioso fosse aos poucos se enfraquecendo.

Mesmo com a mudança na forma de ensino, podemos verificar que a religiosidade não estava totalmente descartada, pois ela já estava impregnada há alguns séculos e não poderia acabar de maneira tão repentina. Em São José dos Pinhais, em meio aos utensílios solicitados pela professora ao presidente da Província, no ano de 1875, constavam dois quadros, sendo um de Jesus Cristo e outro do imperador Dom Pedro II (PARANÁ, 1875). Constatou-se que o retrato do imperador era algo tão importante quanto à figura de Jesus, mostrando que a religião ainda permanecia internalizada no cotidiano das pessoas. Mesmo que a ênfase dada à religião tenha diminuído, os resquícios da educação religiosa permaneceram por um bom tempo. 
Nesta referida solicitação de materiais escrita pela professora Amélia Carvalho, existia uma lista de utensílios, os quais eram por ela considerados indispensáveis para as aulas do sexo feminino. A lista era composta por:

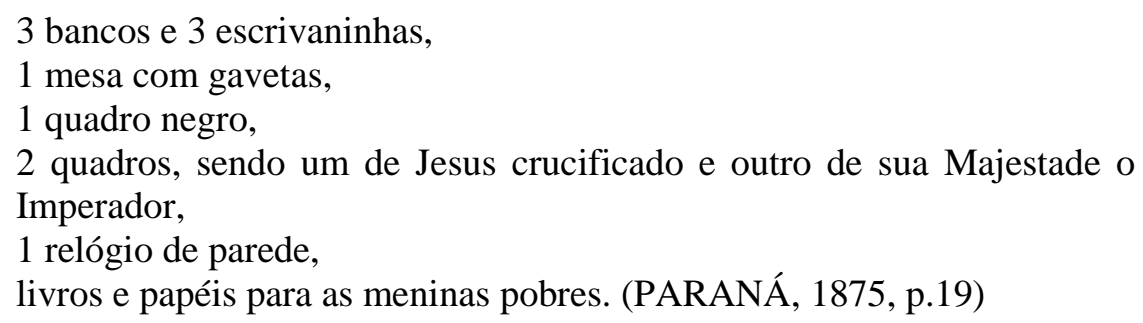

Quando a professora solicitou apenas três bancos e três escrivaninhas podemos inferir que a escola feminina de São José dos Pinhais fosse muito pequena. Somando as três classes juntas essas preenchiam apenas três bancos. Mas, antes lembremos que existiam três classes diferentes e para cada classe existia um banco, como nos alertou Vecchia (1998). Se ela solicitou apenas três bancos era porque havia apenas um banco para cada classe, o que nos mostra que eram poucas as alunas que frequientavam as aulas de Primeiras Letras.

Dentre outros objetos, a professora solicitou também um relógio de parede. O que surgiu como algo inusitado no contexto da época. Por que um relógio seria necessário a este tipo de sala de aula?, sob quais argumentos?. Temos a hipótese de que o controle do tempo tornava-se tarefa de extrema importância para a professora, visto que, ele tinha que controlar o horário de entrada e saída dos alunos, além de ter que ministrar vinte minutos de aula para cada classe e isto seria deveras complexo sem a ajuda de um relógio. $\mathrm{O}$ controle do tempo era dever do professor dentro de sua sala de aula e com isso os alunos iam internalizando o processo de controle e a disciplina da pontualidade.

Outra hipótese para tal solicitação poderia ser a influência dos novos ares de modernidade cultural a partir da criação dos grupos escolares, que existiam nessa época em outras Províncias. O surgimento dos grupos em meados do século XIX ocorreu para organizar e restaurar a instrução pública, instituindo novas formas de controle. Conforme Mimesse (2010), o grupo tinha um diretor durante todo o tempo de funcionamento da escola, um horário específico para as aulas e salas adequadas. O relógio nesse novo contexto era imprescindível ao funcionamento das aulas do Grupo, tanto quanto a existência de uma sineta, a fim de contribuírem com o cumprimento correto da divisão do tempo das atividades escolares.

Em 07 de fevereiro de 1878 o Presidente da Província em exercício, Joaquim Bento de Oliveira Júnior, em item do relatório, descreveu a situação da educação na Província, apontou que não seriam necessárias abrirem novas escolas para melhorar a situação em que se encontrava a instrução pública naquele momento. E, para reforçar e esclarecer suas ideias ele citou os motivos, como seguem: porque seria difícil preencher a escola de forma conveniente. Seria necessária a contratação de mais professores, aumentaria a despesa com o aluguel de mais casas, para servirem de escolas, seria preciso comprar móveis e utensílios, livros e demais utilidades, enfim, o gasto seria muito grande; e pela reduzida frequiência por parte dos alunos, tornaria inútil a criação de novas escolas (PARANÁ, 1878).

Como a baixa freqüência era constante nas escolas de Primeiras Letras da Província, o presidente considerava inútil a manutenção de escolas com baixo número de alunos. Para ele não bastava existirem apenas edifícios, providos de móveis, e "um indivíduo qualquer com o nome de professor" (PARANÁ, 1878, p. 12), era preciso haver 
nas escolas, um mestre, ou seja, uma pessoa que fosse inteligente o suficiente para poder transmitir aos alunos tudo aquilo que pensava. O que, segundo o Presidente, seria difícil de encontrar na Província.

Nas palavras do Presidente, o professor, naquele momento, estava sendo considerado um indivíduo qualquer. Pessoas sem nenhuma aptidão para o ensino tornavam-se professores. Porém, essas eram as únicas pessoas que se dispunham a trabalharem como professores naquele momento, naquela localidade. Contudo, mesmo essas pessoas que foram consideradas inaptas, quando conseguiam outro emprego logo desistiam da carreira do magistério, devido aos baixos salários e pela falta de pagamento dos aluguéis das casas em que as escolas funcionavam. (PARANÁ, 1878).

Em 23 de março de 1878, Rodrigo Otávio de Oliveira Menezes assumiu a presidência da Província do Paraná. Ao tratar da instrução pública em seus relatórios, ele considerava-a lamentável. Enalteceu o estado lastimável em que se encontrava a educação na Província e ainda acrescentou que iria tentar melhoramentos, em caráter de urgência (PARANÁ, 1878). Nesse mesmo relatório, ele concordou com as palavras de seu antecessor, Joaquim Bento, quando este argumentou sobre o estado do magistério em todas as escolas da Província, "[...] o magistério na Província não passa de refúgio a indivíduos que na falta de melhor negocio, o procuram até que descubram novo meio de vida mais commodo. Esta é a triste verdade! (PARANÁ, 1878, p.2)".

Apesar das mudanças na administração da Província, a indignação dos presidentes era sempre redundante. A falta de professores habilitados para o magistério público foi um problema constante a ser enfrentado e, na análise dos Relatórios dos anos de 1856, 1864, 1870 e 1878, percebeu-se que os discursos indicavam que os professores eram os culpados pelo estado precário das escolas e do ensino das Primeiras Letras.

Desde a criação da Província do Paraná a educação foi motivo de inúmeras críticas por parte dos governantes. Em 1854 o presidente da Província escrevia sobre o estado da instrução, e em relatório de 1878, como foi constatado, a situação continuava a mesma. Os professores, quando ainda eram alunos, foram educados de forma precária, levantou-se a hipótese de que essa ação os levou a reproduzirem para seus alunos o que eles próprios aprenderam. Talvez a culpa pela precariedade na educação não devesse recair de forma tão drástica sobre os professores, mas sim pensar por que o governo da província, que sempre soube das más condições de ensino, pouco investiu para amenizar esta situação. Até mesmo a criação da Escola Normal foi algo que, a princípio, não vingou, pois como vimos não existiam pessoas interessadas em frequientar o curso. Considera-se também que persistiam os baixos salários, e esse fato foi marcante que até mesmo o presidente da Província Rodrigo Otávio de Oliveira Menezes em 1878 citou esta questão em seu relatório.

Tratando-se de culpabilidade, temos de verificar a parte que tange aos presidentes da província que apontavam suas reclamações para a falta de habilitação dos professores. Por outro lado temos os professores, que verificavam quais eram os problemas constantes nas escolas, e esses estavam sempre relacionados à ausência dos alunos.

O inspetor Ferreira Bello queixou-se também da falta de aproveitamento nas aulas pelos alunos e o motivo encontrado por ele, para o baixo rendimento dos alunos, foi a pouca frequiência. Para esse inspetor, os pais ocupavam seus filhos com outras tarefas, com as quais eles não conseguiam conciliar o trabalho e o aprendizado. A mão de obra barata, ou totalmente sem custo, fornecida pelos alunos aos seus pais, era o principal motivo das ausências (PARANÁ, 1878).

Em meio a esses problemas, o inspetor de São José dos Pinhais fez um elogio aos professores. Ao da cadeira do sexo masculino por que "mostra aptidão para o magistério e 
desempenha bem sua funcção" (PARANÁ, 1875, p. 25) e, a da cadeira do sexo feminino quando reconhece que esta havia adquirido sua habilitação para o magistério. Como a maioria dos professores não tinha habilitação para o ensino, ter uma professora habilitada e ter um professor com bom desempenho e com aptidão, era um privilégio para a localidade. O inspetor estava na contramão dos discursos dos presidentes analisados até o momento.

Segundo relatório enviado ao presidente da Província pela professora Amélia Carvalho, suas alunas se ausentavam das aulas sem dar notícias e as poucas que retornavam, depois de meses, vinham sem papéis, sem livros e sem penas, objetos indispensáveis para as aulas. Quando a professora solicitava os materiais didáticos necessários às suas pupilas, por vezes, corria o risco de ser insultada por pais que iam até a escola, interferindo no andamento das aulas, para tirarem satisfações sobre a solicitação do material. A professora Amélia Carvalho escreveu ao final de seu relato, que tinha na sua sala de aula três alunas preparadas, duas delas freqüentavam as aulas irregularmente e uma ausentou-se sem dar mais notícias (PARANÁ, 1869). Se de uma turma com três classes, a professora só conseguiu preparar três alunas e duas delas freqüentavam as aulas irregularmente, em que condições de aprendizado estariam as outras alunas, sendo que, as mais preparadas só freqüentavam as aulas algumas vezes? Percebe-se deste modo, a grande dificuldade que existia em ensinar as meninas de São José dos Pinhais naquela época, frustrando as intenções na formação das alunas que a professora mantinha e indo na contracorrente dos discursos dos presidentes da Província.

\section{Considerações finais}

Muitos presidentes assumiram o poder na nova Província brasileira neste período estudado. O discurso em defesa da educação foi mantido, porém poucas foram as mudanças concretas verificadas na documentação analisada. Os discursos dos presidentes indicaram como culpados os professores, eles seriam os responsáveis pelas condições precárias do ensino, porque na maioria das vezes não tinham formação acadêmica específica ou aptidões para o ensino. Por outro lado, as reclamações dos professores, constantes nos documentos, recaiam sobre a ausência dos alunos em sala de aula. Mas, podemos entender as dificuldades enfrentadas por esses professores, eles desenvolviam seus conteúdos apesar da falta de materiais didáticos, de móveis e de utensílios. A maioria das famílias colocava o trabalho e os afazeres domésticos como prioridades, deixando a instrução de suas filhas para segundo plano, redundando na contínua ausência das meninas nas aulas.

Verificou-se neste estudo, segundo a documentação analisada, que a história das escolas de instrução primária na localidade de São José dos Pinhais refletiu a precariedade existente no ensino de toda a Província. Havia uma ampla desordem e uma grande carência na infraestrutura escolar, de modo a inexistirem a maioria dos itens básicos necessários ao funcionamento de uma escola.

Com o passar dos tempos as exigências escolares tornaram-se cada vez maiores, e em contrapartida, os recursos mantiveram-se parcos. Os professores precisavam improvisar, da maneira como pudessem, para conseguirem lecionar e tentarem ensinar o mínimo para seus alunos. As alunas sãojoseenses não conseguiram freqüentar às aulas assiduamente, principalmente porque eram meninas e tinham de trabalhar nos afazeres domésticos. Foi constatado também, conforme a leitura das fontes, que a partir do momento em que as meninas aprendessem a escrever o próprio nome e algumas palavras, ou ainda, a lerem as primeiras frases seus pais não consideravam mais necessário enviá-las 
à escola. Foram raras as alunas que permaneceram mais de um ano consecutivo frequentando as aulas, a resistência das famílias em educá-las era maior.

\section{Referências Bibliográficas}

CERTEAU, M. A Escrita da História. Rio de Janeiro: Forense Universitária, 1982.

COLNAGHI, M. C. São José dos Pinhais: a trajetória de uma cidade. São José dos Pinhais: Prephacio, 1992.

MIMESSE, E. A educação e os imigrantes italianos: da escola de Primeiras Letras ao Grupo Escolar. 2. ed. São Paulo: Iglu, 2010.

SOARES DE ALMEIDA, J. Ler as letras: por que educar meninas e mulheres?. São Bernardo do Campo/SP: Universidade Metodista de São Paulo: Campinas/SP: Autores Associados, 2007.

VECCHIA, A. Imigração e Educação em Curitiba (1853-1889). Tese [Doutorado]. São Paulo: USP,1998.

\section{Fontes}

PARANÁ. Relatórios dos Presidentes da Província do Paraná. Curitiba: Arquivo Público do Estado do Paraná, 15/07/1854, 01/03/1856, 18/11/1864, 15/02/1870, 09/04/1878.

Relatório ao Inspetor da Instrucção Publica de São José dos Pinhais. Curitiba: Arquivo Público do Estado do Paraná, 17/04/1855.

Relatórios ao Presidente da Província do Paraná, enviadas pelos Inspetores da Instrucção Primária de São José dos Pinhais. Curitiba: Arquivo Público do Estado do Paraná, 1869 e 1875.

\section{Notas}

1. Este texto foi originalmente produzido para a apresentação no VIII Congresso Luso-Brasileiro de História da Educação: Infância, Juventude e Relações de Gênero na História da Educação, ocorrido na cidade de São Luís, no Maranhão em agosto de 2010.

2. Os presidentes da Província do Paraná nesta época estudada foram: Zacarias de Góes e Vasconcelos (dez. 1853 a maio 1855); Teófilo Vitório Ribeiro de Rezende (maio 1855 a jul.1855); Henrique Pedro Carlos de Beaurepaire-Rohan (jul. 1855 a mar. 1856); Vicente Pires da Mota (mar. 1856 a set. 1856); José Antônio Vaz de Carvalhaes (set. 1856 a nov. 1857); Francisco Liberato de Matos (nov. 1857 a fev. 1859); Luís Francisco da Câmara Leal (fev. 1859 a maio 1859); José Francisco Cardoso (maio 1859 a mar. 1861); Antônio Barbosa Gomes Nogueira (mar. 1861 a mar. 1863); Manoel Antônio Ferreira (mar. 1863 a jun. 1863); Sebastião Gonçalves da Silva (jun. 1863 a mar. 1864); José Joaquim do Carmo Júnior (mar.1864 a jun. 1864); André Augusto de Pádua Fleury (jun. 1864 a ago. 1864); Agostinho Ermelino de Leão (ago. 1864 a nov. 1864); André Augusto de Pádua Fleury (nov. 1864 a jun. 1865); Manuel Alves de Araújo (jun. 1865 a ago. 1865); André Augusto de Pádua Fleury (ago. 1865 a mar. 1866); Agostinho Ermelino de Leão (mar. 1866 a nov. 1866); Polidoro César Burlamaque (nov. 1866 a ago. 1867); Carlos Augusto Ferraz de Abreu (ago. 1867 a out. 1867); José Feliciano Horta de Araújo (out. 1867 a maio 1868); Carlos Augusto Ferraz de Abreu (maio 1868 a set. 1868); Antônio Augusto da Fonseca (set. 1868 a ago. 1869); Agostinho Ermelino de Leão (ago. 1869 a nov. 1869); Antônio Luís Afonso de 
Carvalho (nov. 1869 a abril 1870); Agostinho Ermelino de Leão (maio 1870 a dez. 1870); Venâncio José de Oliveira Lisboa (dez. 1870 a jan. 1873); Manuel Antônio Guimarães (jan. 1873 a jun. 1873); Frederico José Cardoso de Araújo Abranches (jun. 1873 a maio 1875); Agostinho Ermelino de Leão (maio 1875 a maio 1875); Adolfo Lamenha Lins (maio 1875 a jul. 1877); Manuel Antônio Guimarães (jul. 1877 a ago. 1877); Joaquim Bento de Oliveira Júnior (ago. 1877 a fev. 1878); Jesuíno Marcondes de Oliveira e Sá (fev. 1878 a mar. 1878); Rodrigo Otávio de Oliveira Meneses (mar. 1878 a mar. 1879); Jesuíno Marcondes de Oliveira e Sá (mar. 1879 a abril 1879).

Recebido em: $17 / 12 / 10$

Aprovado em: 07/04/11 